https://helda.helsinki.fi

\title{
Type and time of first re-intervention of posterior restorations-13-year scenario at the public dental service
}

\section{Palotie, Ulla}

2020-07-03

Palotie , U \& Vehkalahti , M M 2020 , ' Type and time of first re-intervention of posterior restorations-13-year scenario at the public dental service ' , Acta Odontologica Scandinavica , vol. 78 , no. 5 , pp. 370-376 . https://doi.org/10.1080/00016357.2020.1728378

http://hdl.handle.net/10138/326758

https://doi.org/10.1080/00016357.2020.1728378

unspecified

acceptedVersion

Downloaded from Helda, University of Helsinki institutional repository.

This is an electronic reprint of the original article.

This reprint may differ from the original in pagination and typographic detail.

Please cite the original version. 


\title{
Type and time of first re-intervention of posterior restorations - 13-year scenario at the Public Dental Service
}

Acta Odontologica Scandinavica

\author{
Ulla Palotie
}

ORCID: 0000-0001-9801-4889

City of Helsinki, Department of Social Services and Health Care, Metropolitan Area Department of Oral Special Care, P.O. BOX 6670, FI-00099 Helsinki, Finland.

HUH Oral Diseases Teaching and Dental Care Unit, P.O. BOX 670, FI-00029 HUS, Finland

Department of Oral and Maxillofacial Diseases, Faculty of Medicine, University of Helsinki, P.O. BOX 41, FI-00014 Helsinki, Finland.

Miira M. Vehkalahti

ORCID: 0000-0002-6319-854X

Department of Oral and Maxillofacial Diseases, Faculty of Medicine, University of Helsinki, P.O. BOX 41, FI-00014 Helsinki, Finland.

\section{Corresponding author}

Ulla Palotie, City of Helsinki, Department of Social Services and Health Care, Metropolitan Area Department of Oral Special Care, P.O. BOX 6670, FI-00099 Helsinki. tel. +358405694143, fax +358931042602,e-mail: ulla.palotie@fimnet.fi 


\begin{abstract}

\section{Objectives}

We investigated first re-interventions of two- and three-surface direct restorations on posterior teeth, specifically noting the type and time of the first re-intervention.

\section{Materials and methods}

In 2002, altogether 5542 posterior two- and three-surface composite and amalgam restorations were done for 3051 patients aged 25-30 years at Helsinki City Public Dental Service (PDS). Based on electronic patient records, we analysed all restorations $(n=2445)$ having re-intervention during a 13year follow-up. We recorded type of tooth, restoration size, and type of first re-intervention. The time to re-intervention was the interval between the date of the placement of restoration at year 2002 and its first re-intervention.
\end{abstract}

\title{
Results
}

Restorative treatment was the most common (77.9\%) first re-intervention, followed by endodontics (11.5\%), extractions (5.2\%), and other (5.4\%). Males, more frequently than females, had extraction or endodontics as first re-intervention. The average time to re-intervention was 5.7 years (SD 3.8; median 5.2). Both median and mean times were shortest for cases involving endodontics or extractions.

\section{Conclusions}

For the majority of two- and three-surface posterior restorations, the first re-intervention is restorative (replacement or repair of restoration). The shortest time to re-intervention is for restorations that have endodontics or extraction as the first re-intervention.

Key words: Amalgam, Composite, Dental restoration failure, Re-intervention, Public Dental Service 


\section{Introduction}

During the last 20 years the rate of replacement of restorations compared with primary restorations has been increasing worldwide, as reviewed recently by Eltahlah et al. [1]. In Norway, repair and replacement of restorations together accounted for $45 \%$ of all restorative treatments provided according to a questionnaire study at Public Dental Service (PDS) [2]. Replacement or repair of restoration, however, is only one type of re-intervention after placement of direct restoration; other types involve endodontic treatment, or extraction, the latter being a terminal solution.

\section{Types of re-intervention}

The re-interventions of restorations can be classified as early and late failures as shown in the metaanalysis based on prospective and retrospective clinical studies [3]. Among the early failures, endodontic type is the most common during the first year of a restoration's service, whereas later failures are related to secondary caries or fractures [3]. Accordingly, the cross-sectional surveys conducted by Mjör and co-workers [4-10] conclude that secondary caries and fractures are the most common reasons for replacement of both composite resin and amalgam restorations. These surveys, however, do not report outcome measures such as endodontics or extractions.

Evidence from a prospective Dental Practice Based Research (DPBR) cohort study in the USA shows that out of over 6000 restorations followed for two years, $6 \%$ were recorded as failed [11]. Most of the reasons for failure were caries or restoration-related (61\%), the remainder comprising endodontic origin (7\%), extraction (6\%), pain or sensitivity $(6 \%)$, and miscellaneous $(19 \%)$ [11]. In England, 1744 tooth were restored at baseline, and every fourth restoration had re-intervention and $7 \%$ of teeth were extracted during a four-year follow-up at National Health Service (NHS) with selected general dental practitioners [12]. A retrospective cohort study among young adults (mean age 22 years) in the Navy and US Marine Corps consisting of over 1050 posterior composite and amalgam restorations reported that during a mean observation period of 2.8 years the overall 
replacement rate was $5.7 \%$ [13], but the reasons for replacement were not disclosed and measured outcome did not include endodontics or extractions.

After direct restorative treatment, $17 \%$ of premolar and molars were extracted according to the data mining study at General Dental Services in England and Wales with a 15-year follow-up of 13 million restorations [14], but all sizes of restorations were analysed. In addition, $11 \%$ of premolar or molar restorations underwent re-intervention within one year and $49 \%$ within 15 years of the initial placement $[14,15]$. A recent data mining of the German Health Insurance database involving 15 million posterior restorations revealed that every fifth two-surface restoration underwent reintervention and 5\% were extracted during a four-year follow-up [16].

In Finland, replacement of restoration accounted for 37\% of the reasons for restoration among 20to 35 -year-olds in a cross-sectional study of 3057 restorations; the majority of restorations ( $82 \%)$ being composite at Helsinki City PDS [17]. No data about the volume or numbers of endodontics or extractions after direct restorative treatment are available from PDS in Finland.

\section{Time to re-intervention}

In the past 20 years, the age of restoration i.e. the time to failure was typically reported with cross sectional surveys where participants from both PDS and private sector filled out questionnaires [1, 4-10, 18-20]. Time to re-intervention refers here to the interval from restoration's initial placement to its first re-intervention or failure, being based on actual incidents retrieved from surveys. According to results from cross-sectional studies, the median or mean age of failed Class II composite restorations in adults is four to six years, and for failed Class II amalgam restoration it is 10 to 16 years in the Nordic countries $[4,6,18]$. Among 20- to 39 -year-olds in Finland at early 
$21^{\text {st }}$ century the median age of failed composite restorations was 4 years and 10.5 years for amalgam restorations [19], but the types of tooth or sizes of restorations were not specified.

\section{Background}

In Finland, oral health services for adults are available in both the public and private sectors. The population:dentist ratio was $1146: 1$ in 2004 , when $23.5 \%$ of the adult population visited public sector dentists and $24.6 \%$ used private sector services [21]. In the public sector, adult patients pay fixed fees that are highly subsidized and notably smaller than those in the private sector. Restorative treatments with direct methods form a considerable part of all dental treatments for adults, in 2009 accounting for approximately 1.5 million procedures in the public sector [22] and 1.9 million procedures in the private sector [23].

Helsinki City PDS (population of about 0.6 million) employed around 170 dentists in 2001 and offered all types of dental services as needed. PDS dentists receive a fixed monthly salary and additional payments based on types and numbers of treatments provided. The dentists are allowed to participate in continuing education sessions during working hours. Electronic data contain individual patient documents providing detailed information recorded by visit and by tooth for all treatment procedures, using official codes, uniform to all service providers. In addition, recordings by restoration give information on the surfaces restored and the materials used.

The aim of this study was to evaluate the type and time of first re-intervention of two- and threesurface direct restorations on posterior teeth. In addition, we aimed to examine the exact time to reintervention based on actual incidents performed at 'real-life' dental appointments. The working 
hypothesis were 1) the majority of re-interventions involve restorative treatment (replacement or repair of restoration) 2) time to re-intervention is longer for amalgam compared to composite.

\section{Materials and methods}

Data are based on electronic patient records retrospectively; original recordings were made at each appointment according to the strictly regulated coding of the National Institute for Health and Welfare (THL) in Finland. The City of Helsinki Department of Social Services and Health Care approved the study protocol.

In 2002, altogether 5542 posterior two- and three-surface composite and amalgam restorations in 3051 patients aged 25-30 years were performed by the Helsinki City PDS [24]. Our previous paper estimated longevity of restoration in 13-year follow-up: altogether 2445 restorations had reintervention, the first re-interventions being analysed in the present study. The mean age of these patients was 27.6 (SD 1.7) years and 61\% were women, mean DMFT was 14.2 (SD 5.7).

All information about direct composite and amalgam restorations is based on electronic patient records where teeth are numbered according to the ISO 3950 system; we later categorized teeth as premolar or molar and as upper or lower jaw. Restorations were classified as either two-surface: Mesio Occlusal (MO) and Disto Occlusal (DO), or three-surface: Mesio Occlusal Distal (MOD). From the patient records using the codes set by the THL, types of re-intervention were categorized as restorative treatment (replacement or repair of restoration), endodontics, extraction, or other (e.g. occlusion adjustment, unspecified emergency treatment). Re-intervention included those procedures involving the same surfaces as the initial restoration in 2002 [24]. The first re-intervention indicated 
failure. The date of the first restoration and the date of the re-intervention were recorded. We calculated the interval from the restoration at year 2002 to the following first re-intervention to an accuracy of one day; this interval was the time to first re-intervention further categorized into quintiles Q1-Q5.

\section{Statistical methods}

Descriptive statistics included medians, means, standard deviations (SDs), 95\% confidence intervals (95\% CIs), and quintiles. Box-plot graphics illustrated distributions of the time to first reintervention. To evaluate differences between the groups, we used Chi-squared tests for frequencies and one-way ANOVA for mean values. Analyses were performed with Survo MM software (version 3.4.1; Survo Systems, Helsinki, Finland).

\section{Results}

During a 13-year follow-up 2445 restorations had re-intervention, i.e. $44.1 \%$ of all posterior twoand three surface restorations placed in 2002 for 25-30 year olds at Helsinki PDS. Table 1 describes the characteristics of the failed restorations $(n=2445)$. Failure of a restoration occurred significantly more frequently in molar teeth, the lower jaw, and three-surface restorations than in premolars, the upper jaw, and two-surface restorations $(\mathrm{p}<0.001)$.

Restorative treatment was the most common (77.9\%) of the first re-interventions, followed by endodontics (11.5\%), extractions (5.2\%), and other (5.4\%). Table 2 presents detailed information on characteristics of teeth and failed restorations by type of the first re-intervention. The type of restoration in year 2002 was significant with regard to the type of re-intervention $(p<0.020)$; MO restorations dominated with restorative treatment, DO and MOD restorations dominated with 
endodontics, and MOD restorations dominated with extractions. The type of re-intervention was significantly associated with patient's gender $(\mathrm{p}<0.001)$. Females more frequently had restorative treatment than males; the opposite was true with extraction, endodontics, or other (Table 2).

Figure 1 shows distributions of the time to re-intervention according to the type of first reintervention. Regarding restorative treatment, the median time to re-intervention was 5.7 years. Both median and mean times were shortest for cases involving endodontics and extractions. The average time to re-intervention was 5.7 years (SD 3.8; median 5.2). Table 3 shows the time to reintervention according to characteristics of teeth and restorations. Differences according to the tooth type and the type and material of restoration were significant $(\mathrm{p}<0.001)$, but no gender differences emerged.

The upper limits of the quintiles of time to first re-intervention were 1.98 years for Q1, 3.91 years for Q2, 6.49 years for Q3, 9.76 years for Q4, and 13.73 years for Q5. Table 4 shows the distribution of first re-interventions within each quintile according to the characteristics of teeth, restorations, and patient gender. Differences by quintiles were statistically significant. Restorative treatment (replacement or repair of restoration) was the most common re-intervention in all quintiles. In Q1, extraction was the first re-intervention for every 10 th restoration in males and for $8.2 \%$ of threesurface restorations. The longer the time to the first re-intervention, the greater the proportion of restorative treatment.

\section{Discussion}

The first re-intervention for the majority of failed two- and three-surface posterior restorations in adults was restorative treatment (replacement or repair of restoration) as we had hypothesized. 
Restorations in molars and covering three surfaces had shorter time to re-intervention than premolar or two-surface restorations. The shortest time to re-intervention was for restorations that had endodontics or extraction as the first re-intervention. Replacement or repair of restoration remained a major re-intervention throughout the quintiles.

In detail, men more frequently than women had extraction or endodontic treatment as the first reintervention, and these re-interventions also occurred sooner in men. Generally, men tend to seek dental treatment later, when the situation with their teeth is more advanced [25], complicating the treatment. Gender differences exist in habitual utilization of health services; more women than men report having visited a dentist in the past 12 months, 58\% vs. 51\% [26]. In view of the symptomless nature of dental diseases in the early and even later stages, especially men should be encouraged to attend regular dental check-ups.

Our results show that the longer the time to the first re-intervention, the more frequently it is a restorative treatment (replacement or repair of restoration), while a shorter time is more often associated with endodontics or extraction, these findings being in line with a meta-analysis [3]. This meta-analysis, however, is based on prospective or retrospective studies involving only a few operators, and restorations were performed under special circumstances (e.g. university or private practice settings), with no resemblance to our practice-based study at PDS. Surprisingly, these similar findings suggest that there is practically no difference between selected clinics and general dental practice regarding treatment patterns. This conclusion contradicts an earlier questionnaire study, where restorative treatment decisions were clearly different depending on the working sector of Finnish dentists [27]. Others have found that patient- and dentist-related factors contribute to the frequency and type of re-intervention [13, 28-32]. In our study, the patient selection was homogenous regarding the patient age (25-30-year-olds) and gender, but unfortunately operating 
dentists' background information was not available due to strict privacy regulations at the Helsinki PDS.

In line with our results, restorations extending to multiple surfaces and posterior tooth type have both been associated with higher frequency of re-intervention [13, 28, 29]. In addition, changing the dentist increases the risk of re-intervention [30, 31]. At Helsinki City PDS, it is common that the treating dentist is not the same from one appointment to another, especially before and after the emergency dental treatment.

The dentist's decision-making in observing or approaching an existing restoration is critical for future restoration [33]. Proactive and reactive profile types have been proposed as decision-making styles for dentists [28], but thus far no research results have emerged. In our study, replacement or repair of restoration was the most common re-intervention which is in line with study by Clarkson et al. [12]. Recently Linden et al. [34] have reported that the number of restorative treatment measures among children and adolescents at PDS has dramatically decreased ( $>50 \%)$ from 2001 to 2013, but data concerning adults are not available. Regarding the re-intervention option of tooth extraction, studies with much shorter follow-ups than ours have reported extraction rates of 5-7\% after restorative treatment $[11,12,29]$, in accord with our findings.

In our practice-based study the time to re-intervention describes the interval to actual incidents i.e. the time to failure, which in the earlier cross-sectional surveys was called 'age of restoration'. Longevity of restorations, on the other hand, is estimated by e.g. Kaplan-Meier method [3, 14-16, $24,35]$ which predicts theoretical longevity by taking into account all restorations: failed and not failed between date of placement and the end of the observation period. Indeed, this method is based on the hazard function, therefore producing calculations which are at their best only 
estimates. There seems to be a disagreement of best method how to present the age of restoration or its longevity; 'age of restoration' is based on surveys, and has been acknowledged by Jokstad and Mjör [36], but later others have disagreed [35, 37, 38], mainly because failed incidents could have been recorded unreliably. Longevity and time to re-intervention, from our perspective, both describe different dimensions of restoration's lifespan: estimates of longevity against actual numbers about the time to first re-intervention. Strength of our study lies in these 'real-life' incidents and authentic practice-based recordings which were tracked for 13 years.

In our study, the mean time to re-intervention was 5.7 years (SD 3.8), which is in line with earlier cross-sectional surveys regarding failed composite restorations among adults in the Nordic countries at general dental practice $[6,18,19]$. Amalgam restorations, by contrast, have had longer mean or median ages than ours when investigated with cross-sectional methods $[6,18,19]$. Thus our second working hypothesis was not supported. However, these earlier studies were conducted over the decades when mainly amalgam was used, resulting in longer ages [35]. At PDS in Finland, the transition from amalgam to composite restorations was rather rapid, occurring in the late 1990s [39]. In our study, amalgam restorations were the clear minority. Furthermore, two- to three-surface amalgams were probably used only for clinically challenging cases.

In conclusion, restorative treatment (replacement or repair of restoration) is the major reason for the first re-intervention among adults at Helsinki City PDS, and patient's gender differences exist by type of re-intervention. The shortest time to re-intervention is for restorations in teeth that have endodontics or extraction as the first re-intervention. Further research is needed to identify the more accurate reasons for the short time to re-intervention and to assess the specific reasons behind early failures due to endodontics and extractions. In addition, exploring of dentist-related factors (including changing the treating dentist) and patient-related factors behind different types of re- 
interventions at PDS are recommended in future. Proposed practical implications are continuing education and sharing our results to general dental practitioners at Helsinki City PDS.

\section{Acknowledgements}

We thank the Helsinki City PDS for placing their data at our disposal. Tuomo Maisala is thanked for selecting the cases and Marjut Grainger for invaluable help with data cleaning.

\section{Declaration statement}

The authors report no conflict of interest.

\section{Funding}

This work was financially supported by a personal grant to Ulla Palotie from the Finnish Dental

Society Apollonia and the City of Helsinki, Department of Social Services and Health Care. 
Table 1. Proportions of failed restorations during a 13-year observation according to characteristics of teeth and restorations. The baseline restorations were performed on premolars and molars of $25-$ to 30 -year-old patients in 2002.

\begin{tabular}{|c|c|c|c|}
\hline $\begin{array}{l}\text { Characteristics of teeth and } \\
\text { restorations }\end{array}$ & $\begin{array}{c}\text { Restorations placed in } 2002 \\
\mathrm{~N}\end{array}$ & $\begin{array}{c}\text { Restorations failed in } 13 \text { years } \\
\mathrm{n}(\%)\end{array}$ & $p$-value \\
\hline All restorations & 5542 & 2445 (44.1) & \\
\hline Type and site of tooth & & & $<0.001$ \\
\hline Upper premolar & 1630 & $591(36.3)$ & \\
\hline Lower premolar & 586 & $173(29.5)$ & \\
\hline Upper molar & 1511 & 720 (47.7) & \\
\hline Lower molar & 1815 & 961 (52.9) & \\
\hline Type of tooth & & & $<0.001$ \\
\hline Premolar & 2216 & 764 (34.5) & \\
\hline Molar & 3326 & $1681(50.5)$ & \\
\hline Type of jaw & & & $<0.001$ \\
\hline Upper jaw & 3141 & $1311(41.7)$ & \\
\hline Lower jaw & 2401 & $1134(47.2)$ & \\
\hline Type of restoration & & & $<0.001$ \\
\hline Mesio-occlusal & 2163 & 949 (43.9) & \\
\hline Disto-occlusal & 2550 & $1060(41.6)$ & \\
\hline Larger (MOD) & 829 & $436(52.6)$ & \\
\hline Material of restoration & & & 0.06 \\
\hline Amalgam & 373 & $182(48.8)$ & \\
\hline Composite & 5169 & $2263(43.8)$ & \\
\hline Patient's gender & & & 0.21 \\
\hline Male & 2154 & $973(45.2)$ & \\
\hline Female & 3388 & 1472 (43.4) & \\
\hline
\end{tabular}

Statistical evaluation: Chi-squared tests 
Table 2. Distributions (\%) of the first re-interventions $(n=2445)$ according to characteristics of teeth and restorations placed in premolars and molars of 25- to 30-year-old patients in 2002.

\begin{tabular}{|c|c|c|c|c|c|c|}
\hline \multirow{3}{*}{$\begin{array}{l}\text { Characteristics of teeth and } \\
\text { restorations at baseline }\end{array}$} & \multicolumn{6}{|c|}{ Type of first re-intervention (\%) } \\
\hline & & Restorative & Endodontics & Extraction & Other & $\mathrm{p}$-value \\
\hline & $\mathrm{n}$ & $\%$ & $\%$ & $\%$ & $\%$ & \\
\hline Total & 2445 & 77.9 & 11.5 & 5.2 & 5.4 & \\
\hline Type and site of tooth & & & & & & 0.763 \\
\hline Upper premolar & 591 & 76.8 & 12.5 & 4.4 & 6.3 & \\
\hline Lower premolar & 173 & 79.2 & 9.2 & 5.8 & 5.8 & \\
\hline Upper molar & 720 & 78.1 & 11.5 & 4.7 & 5.7 & \\
\hline Lower molar & 961 & 78.1 & 11.3 & 5.9 & 4.6 & \\
\hline Type of tooth & & & & & & 0.623 \\
\hline Premolar & 764 & 77.4 & 11.8 & 4.7 & 6.2 & \\
\hline Molar & 1681 & 78.1 & 11.4 & 5.4 & 5.1 & \\
\hline Type of jaw & & & & & & 0.241 \\
\hline Upper jaw & 1311 & 77.5 & 12.0 & 4.6 & 5.9 & \\
\hline Lower jaw & 1134 & 78.3 & 11.0 & 5.9 & 4.8 & \\
\hline Type of baseline restoration & & & & & & 0.020 \\
\hline Mesio-occlusal & & & & & & \\
\hline Disto-occlusal & 949 & 80.2 & 9.8 & 4.3 & 5.7 & \\
\hline Larger (MOD) & 1060 & 77.5 & 12.8 & 4.8 & 4.9 & \\
\hline & 436 & 73.9 & 12.2 & 8.0 & 6.0 & \\
\hline Material of restoration & & & & & & 0.219 \\
\hline Amalgam & 182 & 74.2 & 11.0 & 8.2 & 6.6 & \\
\hline Composite & 2263 & 78.2 & 11.6 & 4.9 & 5.3 & \\
\hline Patient's gender & & & & & & \\
\hline Male & 973 & 73.4 & 13.1 & 7.2 & 6.4 & $<0.001$ \\
\hline Female & 1472 & 80.8 & 10.5 & 3.9 & 4.8 & \\
\hline
\end{tabular}

Statistical evaluation: Chi-squared tests 
Table 3. Time to re-intervention of the two- and three-surface restorations according to characteristics of teeth and restorations placed in premolars and molars of 25- to 30-year-old patients in 2002.

\begin{tabular}{|c|c|c|c|c|c|}
\hline \multirow{2}{*}{$\begin{array}{l}\text { Characteristics of teeth and } \\
\text { restorations }\end{array}$} & \multicolumn{5}{|c|}{ Time to re-intervention (years) } \\
\hline & $\mathrm{n}$ & Median & Mean (SD) & $95 \% \mathrm{Cl}$ & $p$-value \\
\hline Total & 2445 & 5.2 & $5.7(3.8)$ & $5.6-5.9$ & \\
\hline Type and site of tooth & & & & & $<0.001$ \\
\hline Upper premolar & 591 & 6.0 & $6.3(4.0)$ & $5.9-6.6$ & \\
\hline Lower premolar & 173 & 6.1 & $6.3(3.8)$ & $5.8-6.9$ & \\
\hline Upper molar & 720 & 4.8 & $5.5(3.8)$ & $5.2-5.8$ & \\
\hline Lower molar & 961 & 5.0 & $5.5(3.7)$ & $5.2-5.7$ & \\
\hline Type of tooth & & & & & $<0.001$ \\
\hline Premolar & 764 & 6.0 & $6.3(3.9)$ & $6.0-6.5$ & \\
\hline Molar & 1681 & 4.9 & $5.5(3.8)$ & $5.3-5.7$ & \\
\hline Type of jaw & & & & & 0.130 \\
\hline Upper jaw & 1311 & 5.3 & $5.8(3.9)$ & $5.6-6.1$ & \\
\hline Lower jaw & 1134 & 5.1 & $5.6(3.7)$ & $5.4-5.8$ & \\
\hline Type of baseline restoration & & & & & $<0.001$ \\
\hline Mesio-occlusal & 949 & 5.3 & $5.8(3.9)$ & $5.6-6.1$ & \\
\hline Disto-occlusal & 1060 & 5.5 & $6.0(3.8)$ & $5.7-6.2$ & \\
\hline Larger (MOD) & 436 & 4.3 & $4.9(3.6)$ & $4.6-5.3$ & \\
\hline Material of restoration & & & & & $<0.001$ \\
\hline Amalgam & 182 & 3.8 & $4.8(3.5)$ & $4.3-5.3$ & \\
\hline Composite & 2263 & 5.3 & $5.8(3.9)$ & $5.6-6.0$ & \\
\hline
\end{tabular}

Statistical evaluation: One-way ANOVA 
Table 4. Distributions ( $\%)$ of the failed two- and three-surface restorations $(n=2445)$ placed in posterior teeth of 25- to 30-year-old patients in 2002 according to the type of first re-intervention separately by quintiles (Q1-Q5) of the time to re-intervention.

\begin{tabular}{|c|c|c|c|c|c|c|}
\hline \multirow{5}{*}{$\begin{array}{l}\text { Characteristics and numbers } \\
\text { of teeth and restorations; type } \\
\text { of first re-intervention }\end{array}$} & \multicolumn{5}{|c|}{ Quintiles with upper limits of the time to first re-intervention } & \multirow{5}{*}{ p-value } \\
\hline & Q1 & Q2 & Q3 & Q4 & Q5 & \\
\hline & 1.98 years & 3.91 years & 6.49 years & 9.76 years & 13.73 & \\
\hline & & & & & years & \\
\hline & $\%$ & $\%$ & $\%$ & $\%$ & $\%$ & \\
\hline All teeth $(n=2445)$ & & & & & & $<0.001$ \\
\hline Restorative & 77.4 & 74.0 & 74.1 & 80.8 & 83.1 & \\
\hline Endodontics & 16.3 & 14.5 & 12.4 & 7.1 & 7.2 & \\
\hline Extraction & 5.9 & 6.1 & 5.1 & 5.3 & 3.5 & \\
\hline Other & 0.4 & 5.3 & 8.4 & 6.7 & 6.2 & \\
\hline Premolars ( $n=764)$ & & & & & & 0.001 \\
\hline Restorative & 76.6 & 72.5 & 72.8 & 80.3 & 82.6 & \\
\hline Endodontics & 18.8 & 16.0 & 14.6 & 5.1 & 7.4 & \\
\hline Extraction & 4.7 & 5.3 & 4.4 & 7.0 & 2.6 & \\
\hline Other & 0.0 & 6.1 & 8.2 & 7.6 & 7.4 & \\
\hline Molars ( $n=1681$ ) & & & & & & $<0.001$ \\
\hline Restorative & 77.7 & 74.6 & 74.7 & 81.1 & 83.4 & \\
\hline Endodontics & 15.4 & 14.0 & 11.4 & 8.1 & 7.1 & \\
\hline Extraction & 6.3 & 6.4 & 5.4 & 4.5 & 4.1 & \\
\hline Other & 0.6 & 5.0 & 8.4 & 6.3 & 5.4 & \\
\hline Mesio-occlusal ( $n=949)$ & & & & & & 0.002 \\
\hline Restorative & 81.6 & 75.2 & 77.4 & 82.1 & 84.2 & \\
\hline Endodontics & 12.8 & 12.7 & 13.1 & 4.6 & 6.4 & \\
\hline Extraction & 5.1 & 5.8 & 2.4 & 5.1 & 3.0 & \\
\hline Other & 0.5 & 6.3 & 7.1 & 8.2 & 6.4 & \\
\hline Disto-occlusal $(n=1060)$ & & & & & & $<0.001$ \\
\hline Restorative & 73.1 & 75.3 & 73.2 & 81.6 & 83.2 & \\
\hline Endodontics & 21.0 & 14.7 & 12.3 & 9.2 & 8.4 & \\
\hline Extraction & 5.4 & 4.3 & 5.9 & 5.1 & 3.5 & \\
\hline Other & 0.5 & 5.7 & 8.6 & 4.1 & 4.9 & \\
\hline Three-surface (MOD) ( $n=436)$ & & & & & & 0.015 \\
\hline Restorative & 77.3 & 68.5 & 70.6 & 75.6 & 78.9 & \\
\hline Endodontics & 14.5 & 18.0 & 11.8 & 7.7 & 5.3 & \\
\hline Extraction & 8.2 & 11.2 & 7.8 & 6.4 & 5.3 & \\
\hline Other & 0.0 & 2.2 & 9.8 & 10.3 & 10.5 & \\
\hline Male patients ( $n=973$ ) & & & & & & $<0.001$ \\
\hline Restorative & 70.3 & 65.1 & 71.4 & 77.8 & 82.7 & \\
\hline Endodontics & 19.0 & 19.1 & 14.1 & 6.7 & 6.6 & \\
\hline Extraction & 10.1 & 7.9 & 7.0 & 7.2 & 4.1 & \\
\hline Other & 0.6 & 7.9 & 7.5 & 8.2 & 6.6 & \\
\hline Female patients ( $n=1472)$ & & & & & & $<0.001$ \\
\hline Restorative & 81.1 & 81.1 & 76.0 & 82.8 & 83.4 & \\
\hline Endodontics & 14.9 & 10.9 & 11.3 & 7.4 & 7.6 & \\
\hline Extraction & 3.7 & 4.7 & 3.8 & 4.1 & 3.1 & \\
\hline Other & 0.3 & 3.3 & 8.9 & 5.7 & 5.9 & \\
\hline
\end{tabular}

Statistical evaluation: One-way ANOVA 
Figure 1. Box-plot of time to re-intervention of two- and three-surface restorations according to type of first re-intervention $(n=2445)$ in posterior teeth of 25 - to 30 -year-old patients in 2002 . $\mathrm{X}=$ mean, bolded line $=$ median, boxes $\&$ whiskers $=$ quartiles, circles $=$ outliers.

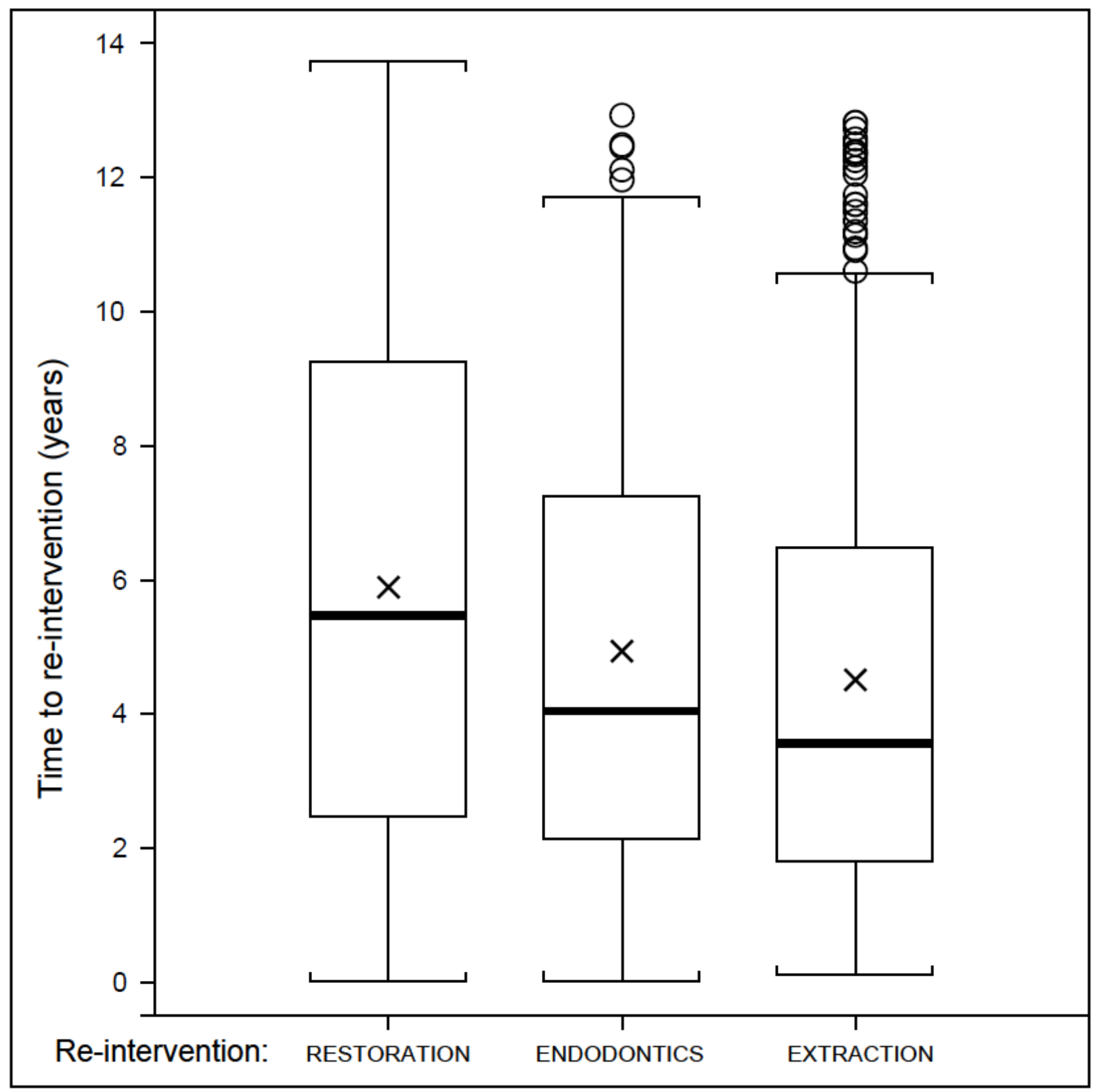




\section{References}

[1] Eltahlah D, Lynch CD, Chadwick BL, et al. An update on the reasons for placement and replacement of direct restorations. J Dent. 2018;72:1-7.

[2] Staxrud F, Tveit AB, Rukke HV, et al. Repair of defective composite restorations. A questionnaire study among dentists in the Public Dental Service in Norway. J Dent. 2016;52:50-54. [3] Opdam NJM, van de Sande FH, Bronkhorst E, et al. Longevity of Posterior Composite Restorations. J Dent Res. 2014;93:943-949.

[4] Mjör IA. The reasons for replacement and the age of failed restorations in general dental practice. Acta Odontol Scand. 1997;55:58-63.

[5] Mjor IA, Shen C, Eliasson ST, et al. Placement and replacement of restorations in general dental practice in Iceland. Oper Dent. 2002;27:117-123.

[6] Mjör IA, Dahl JE, Moorhead JE. Age of restorations at replacement in permanent teeth in general dental practice. Acta Odontol Scand. 2000;58:97-101.

[7] Qvist V, Qvist J, Mjör IA. Placement and longevity of tooth-colored restorations in Denmark. Acta Odontol Scand. 1990;48:305-311.

[8] Mjör IA, Toffenetti F. Placement and replacement of amalgam restorations in Italy. Oper Dent. 1992;17:70-73.

[9] Mjör IA, Toffenetti F. Placement and replacement of resin-based composite restorations in Italy. Oper Dent. 1992; 7:82-85.

[10] Qvist J, Qvist V, Mjör IA. Placement and longevity of amalgam restorations in Denmark. Acta Odontol Scand. 1990;48:297-303.

[11] McCracken MS, Gordan VV, Litaker MS, et al. A 24-month evaluation of amalgam and resinbased composite restorations. J Am Dent Assoc. 2013;144:583-593.

[12] Clarkson JE, Worthington HV, Davies RM. Restorative treatment provided over five years for adults regularly attending general dental practice. J Dent. 2000;28:233-239.

[13] Laccabue M, Ahlf R, Simecek J. Frequency of Restoration Replacement in Posterior Teeth for U.S. Navy and Marine Corps Personnel. Oper Dent. 2014;39:43-49.

[14] Lucarotti PSK, Burke FJT. The ultimate guide to restoration longevity in England and Wales.

Part 1: methodology. BDJ. 2018;224:709-716.

[15] Lucarotti PSK, Burke FJT. The ultimate guide to restoration longevity in England and Wales.

Part 6: molar teeth: restoration time to next intervention and to extraction of the restored tooth.

BDJ. 2018;225:525-536.

[16] Raedel M, Hartmann A, Bohm S, et al. Four-year outcomes of restored posterior tooth surfaces - a massive data analysis. Clin Oral Investig. 2017;21:2819-2825.

[17] Palotie U, Vehkalahti MM. Restorative treatment and use of local anesthesia in free and subsidized public dental services in Helsinki, Finland. Acta Odontol Scand. 2003;61:252-256.

[18] Sunnegårdh-Grönberg K, van Dijken JWV, Funegård U, et al. Selection of dental materials and longevity of replaced restorations in Public Dental Health clinics in northern Sweden. J Dent. 2009;37:673-678.

[19] Forss H, Widström E. From amalgam to composite: selection of restorative materials and restoration longevity in Finland. Acta Odontol Scand. 2001;59:57-62.

[20] Forss H, Widström E. Reasons for restorative therapy and the longevity of restorations in adults. Acta Odontol Scand. 2004;62:82-86.

[21] Niiranen T, Widström E, Niskanen T. Oral Health Care Reform in Finland - aiming to reduce inequity in care provision. BMC Oral Health. 2008;8:3.

[22] Widström E, Linden J, Tiira H, et al. Treatment provided in the public dental service in Finland in 2009. Community Dent Health. 2015;32:60-64.

[23] Reimbursements for dentists' fees: number of recipients. Social Insurance Institute. 2019.

http://raportit.kela.fi/linkki/25368044. Accessed 11 Jan 2020. 
[24] Palotie U, Eronen AK, Vehkalahti K, et al. Longevity of 2- and 3-surface restorations in posterior teeth of 25- to 30-year-olds attending Public Dental Service-A 13-year observation. J Dent. 2017;62:13-17.

[25] Bae JH, Kim YK, Choi YH. Clinical characteristics of dental emergencies and prevalence of dental trauma at a university hospital emergency center in Korea. Dent Traumatol. 2011;27:374378.

[26] Suominen-Taipale L, Nordblad A, Vehkalahti MM, et al. Oral Health in the Finnish adult population. Health 2000 survey. Publications of the National Public Health Institute B 25/2008. Helsinki: Hakapaino; 2008. http://www.julkari.fi/bitstream/handle/10024/103030/2008b25.pdf. Accessed 11 Jan 2020.

[27] Heinikainen M, Vehkalahti M, Murtomaa H. Re-treatment decisions for failed posterior fillings by Finnish general practitioners. Community Dent Health. 2002;19:98-103.

[28] Laske M, Opdam NJM, Bronkhorst EM, et al. Longevity of direct restorations in Dutch dental practices. Descriptive study out of a practice based research network. J Dent. 2016;46:12-17.

[29] Raedel M, Hartmann A, Priess HW, et al. Re-interventions after restoring teeth-Mining an insurance database. J Dent. 2017;57:14-19.

[30] Bogacki RE, Hunt RJ, del Aguila M, et al. Survival analysis of posterior restorations using an insurance claims database. Oper Dent. 2002;27:488-492.

[31] Burke FJT, Lucarotti PSK, Holder RL. Outcome of direct restorations placed within the general dental services in England and Wales (Part 2): Variation by patients' characteristics. J Dent. 2005;33:817-826.

[32] Laske M, Opdam NJM, Bronkhorst EM, et al. Risk Factors for Dental Restoration Survival: A Practice-Based Study. J Dent Res. 2019;98:414-422.

[33] Demarco FF, Collares K, Correa MB, et al. Should my composite restorations last forever?

Why are they failing? Braz Oral Res. 2017;31 suppl 1:92-99.

[34] Linden J, Widström E, Sinkkonen J. Children and adolescents' dental treatment in 2001-2013 in the Finnish public dental service. BMC Oral Health. 2019;19:131.

[35] Opdam NJM, Bronkhorst EM, Cenci MS, et al. Age of failed restorations: A deceptive longevity parameter. J Dent. 2011;39:225-230.

[36] Jokstad A, Mjör IA, Qvist V. The age of restorations in situ. Acta Odontol Scand. 1994;52:234-242.

[37] Vähänikkilä H, Miettunen J, Tjäderhane L, et al. The use of time-to-event methods in dental research: a comparison based on five dental journals over a 11-year period. Community Dent Oral Epidemiol. 2012;40:36-42.

[38] Burke F, Singh V, Wilson N. The Normalized Failure Index: A method for summarizing the results of studies on restoration longevity? Oper Dent. 2013;38:488-496.

[39] Forss H, Widström E. Factors influencing the selection of restorative materials in dental care in Finland. J Dent. 1996;24:257-262. 